\title{
Pedagogical and Psychological Settings for Training of Student Lawyers in Framed Professional Communication
}

\author{
Olena V. Dyshkant ${ }^{{ }^{*}}$ \\ Natalia P. Dichek ${ }^{2}$ \\ Viktor M. Beschastnyy ${ }^{3}$ \\ Viktoriia M. Savishchenko ${ }^{4}$ \\ Viktor Y. Hurskyi ${ }^{5}$ \\ ${ }^{1}$ Department of Innovation, Institute of Public Administration and Research in Civil Protection, Kyiv, Ukraine \\ ${ }^{2}$ Institute of Pedagogy, National Academy of Educational Sciences of Ukraine, Kyiv, Ukraine \\ ${ }^{3}$ Constitutional Court of Ukraine, Kyiv, Ukraine \\ ${ }^{4}$ Faculty of Law, Dnipropetrovsk State University of Internal Affairs, Dnipro, Ukraine \\ ${ }^{5}$ Department of Tactical Special Training, Mariupol, Ukraine
}

DOI: https://doi.org/10.36941/jesr-2021-0107

\section{Abstract}

The purpose of the study was to identify how the training of student lawyers in message framing influences their professional written and verbal communication proficiency. The study used qualitative research methods such as observations and focus groups to yield the data for the analysis. The focus group was used to obtain feedback from the sampled students concerning the training in framing messages. The study found that a specifically structured instructional model that relied on a 'bolt-on' module in message framing delivered throughout the entire elective course in Legal Rhetoric positively influenced students' professional written and verbal communication proficiency. The data drawn from observations showed that students' abilities to use functional language and language rules increased throughout the training. When rating the activities for training in framing messages that are useful for lawyers, the observers mentioned five framing message activities seen as the most effective. Those were as follows: gain and loss, storytelling, WASP, callto-action, ethos, and pathos. Gain and loss, ethos and pathos, and storytelling were rated by the observers higher than WASP and call-to-action. These were considered by the observers to be the most appropriate for the lawyer job context. Data relating to students' general impressions of training in framing messages showed that they found this training interesting and engaging, practically useful for their jobs.

Keywords: higher education, student lawyers, message framing, professional communication

\section{Introduction}

Professional communication skills are considered crucially important for a lawyer willing to be successful in their carrier (Smith, 2020). Training student lawyers (Medical Law and Ethics) in 
framing communication seems to be a way for them to assimilate the sense-making mindset which can help them turn the complexity of legal inputs and consequences into a concise and powerful message. Framing of communication has proven to be an effective approach used by lawyers to perform their job as it focuses on the emotional component of decision making (Arowolo, 2017).

Framing theory is a dimension of the Mass Communication Theory (MCT) and the prospect theory that focuses on the way the issue is presented rather than on a topic of this particular issue (Harley, 2016; Mass Communication Theory, n.d.). The framing theory is consistent with the set of legal principles that are applied to the presentation of the factual context of each problem rather than its theme.

\section{$1.1 \quad$ Literature Review}

The literature review found that framed professional communication is revealed from theoretical and instructional perspectives. Theoretically, message framing is intended to frame decisions and change behaviours (Keyworth et al., 2018; Wicks, 2005). The approach relies on addressing individuals' benefits or the probable consequences for them (Cheng, Woon \& Lynes, 2011). In the context of law, framing helps justify or interpret a fact to influence a message recipient to take a given standpoint or make the final decision (in a judgment or the administrative decision) (Bekrycht, 2014). Framed communication is supposed to be effectively used by the lawyers-to-be in both written and oral communication because the law students' ability to utilize message framing in their job is related to building a client-lawyer relationship which determines the students' career success (Gouvin et al., 2019). Thus, framed communication requires employing not only the specific structure of a written or verbal message but also appropriate content, form, and tone of conveying the ideas which should take into account the type of the addressee and expectations of formality.

The instructional application of training students in framing is discussed by Li, Jain, Shen, and Jain (2020), Pervan and Vocino (2008), Richardson (2010), and Sheil (2017). Li et al. (2020) suggest training negotiators in the use of different message framing strategies to minimise the risk of the unfavourable outcome of negotiations. Richardson (2010) suggests training individuals in leadership by introducing framing for managing meaning. Sheil (2017) opines that framing can ensure a better understanding of one's messages and create the result that one desires. According to Pervan and Vocino (2008), there is a lack of consistency between students' future jobs and educational practice regarding training students in framed communication. The typical exercises to train law students in written communication with the use of framing messages are as follows: 'Letter to Client Exercise', 'Engagement Letter Exercise', 'Cover Memo Exercise', 'E-mail-Only Negotiation Exercise' etc. The typical exercises to train students in oral communication are as follows: 'Peer Debriefing Exercise', 'Initial Client Interview Exercise', 'Code of Conduct Exercise', and 'Presentation Exercise' (Gouvin et al., 2019). The review found a theoretical and practical gap in addressing the problem of training of student lawyers in framed professional communication which suggested it was relevant and feasible.

The purpose of the study was to identify how the training of student lawyers in message framing influences their professional written and verbal communication proficiency.

The study attempted to address the research questions that were as follows:

1) What are the most effective activities for training in framing messages to influence the communication proficiency of student lawyers?

2) How did sampled students perceive the training in framing messages?

\section{Methods and Materials}

The study used qualitative research methods such as observations and focus groups to yield the data for the analysis. The reason for choosing methods was based on the idea that the statistical (quantitative) methods used in communication research such as simple correlation and regression, analyses of variance and covariance do not always provide the researcher with accurate and detailed 
knowledge of changes to have occurred in communication act due to the intervention (Hayes, 2005; Reinard, 2006). The checklist for observations and a questionnaire for a focus group was originally designed and validated to be used as instruments in the intervention. The checklist (see Appendix A) was used to answer the first research question while the questionnaire (see Appendix B) was utilised to answer the second one.

\subsection{Research Design}

The study involves an experiment that relied on a quasi-experiment of non-equivalent control group post-test only design (Price, 2016). The study took two semesters (September 2019 - June 2020) and was organised as a flow of five basic phases. These were as follows: theoretical conceptualisation, preparation, intervention and data collection, data analysis, and dissemination (Hanacek, n.d.). In the phase of theoretical conceptualisation, the research scope and feasibility of the intervention were identified. In the phase of preparation, the intervention materials were developed and piloted, the checklists were developed and validated, and the sampling was conducted. In the phase of the intervention, the training of student lawyers in message framing was run, observations were performed and qualitative data were yielded. In the data analysis phase, the information was consolidated in the Excel file, categorised into themes, analysed, and interpreted. In the phase of dissemination, a webinar was conducted to share the experience with educators and this was followed by producing recommendations (see Fig. 1).

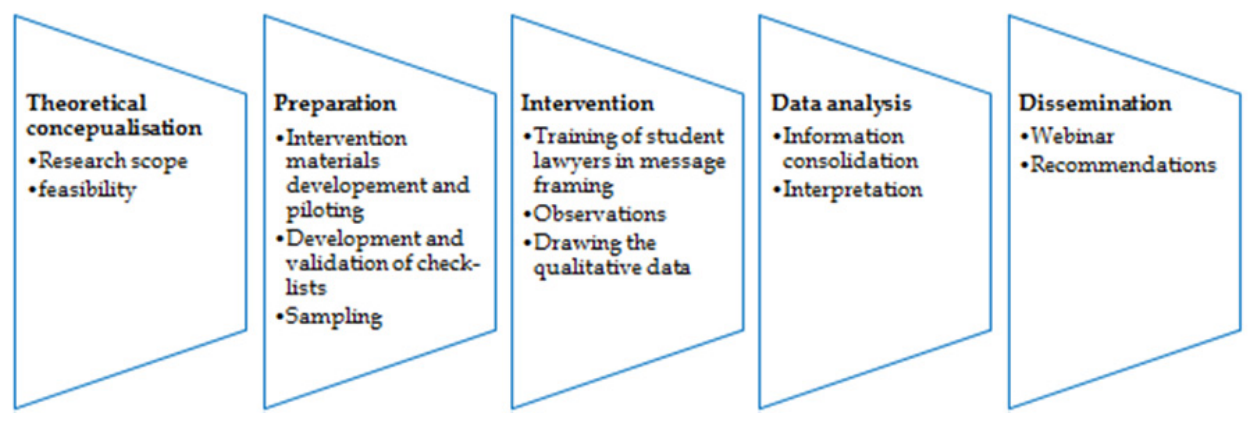

Figure 1: Phases of the study

\subsection{Description of the Intervention}

The intervention was designed as a 'bolt-on' module delivered throughout the entire elective course in Legal Rhetoric lasting 2 ECTS credits (6o hours). The module was not credit-bearing or mapped against aims and learning outcomes set in the programme. The training sessions were conducted to foster student lawyers' professional language abilities comprising written and verbal functional and linguistic ones. The students practiced 14 message frames such as gain and loss, storytelling, call-toaction, signalling and countersignalling, ethos and pathos, nudges, peak-end rule, choice architecture, dumbing down, loaded questions, and WASP (welcome-ask-suggest-part). While in class, the EG students were mingled or assigned in groups to express (orally or in writing) the views or claims, or arguments that were positively or negatively framed. The message word limit could vary from 70 to 120 words.

For instance, the sampled students were assigned to write a 'gain or loss-framed' message about the COVID-19 vaccination to persuade people to get immunised. Before doing the task, the instructor elicited the students' attitudes to vaccination using three scales as a "Bad-to-Good 5-point scale", "Foolish-to-Wise 5-point scale" and "Harmful-to-Beneficial 5-point scale". Following that, the 
students were suggested they outlined their thoughts on positive and negative factors of vaccination (societal and legal), their perceptions of it, and benefits VS consequences of it. Then the students wrote the messages to persuade people to immunise themselves against COVID-19, publish them in the Telegram group through the LikeBot and let the other vote for the best (most persuasive) message. The framed message which scored the most likes was considered the winning.

Each training session was observed by two or three research members and one or two invited experts in communication.

\subsection{Sampling}

Purposive sampling technique of homogeneous sampling form was used to select 83 subjects from a population of 792 undergraduates from Kyiv National Economic University (KNEU), named after Vadym Hetman (Ukraine) and V. N. Karazin Kharkiv National University (Karazin KhNU) (Ukraine) to participate in the study (Etikan, Musa \& Alkassim, 2016). A sample size of 83 students was used to form the experimental and control groups. The experimental group (EG) included 41 students majoring in Law (Medical Law and Ethics Course) at KNEU and the control group (CG) consisted of 42 students studying Law (Medical Law and Ethics Course) at Karazin KhNU. The criteria for inclusion were as follows: 1) the sampled student is a participant of a Legal Rhetoric elective course; 2) the student's grade point average (GPA) is between 85 and 100 ECTS; 3 ) the one is willing to take part in the experiment; 4) the students' mean grade in the Rhetorical Task Examination (RTE) is higher than 100 out of 130. RTE was borrowed from Lazaraton and Riggenbach (1990); see Appendix A and Appendix B. The key reason for including the latter two criteria was based on the implication of Chong and Druckman (2007) and Lee, Liu, and Cheng (2018) who stated that more knowledgeable individuals are more effected by framed messages and easier assimilate the process of message framing. The demographic features of the sampled students and results of selection using the criteria for inclusion are outlined in Table 1.

Table 1: Demographic features of the sampled students and results of selection using the criteria for inclusion drawn from EG and CG

\begin{tabular}{l|l|c|c|c|c}
\hline Feature & KNEU (EG) $(n=41), \%$ & KhNU (CG) $(n=42), \%$ & $\bar{x}$ & $S D$ \\
\hline \multirow{2}{*}{ Gender } & Males & $17(41.46 \%)$ & $22(52.38 \%)$ & 19.5 & 3.53 \\
\cline { 2 - 7 } & Females & $24(58.54 \%)$ & $20(47.62 \%)$ & 22 & 2.82 \\
\hline \multirow{3}{*}{ Age } & 20 & $27(65.85 \%)$ & $24(57.14 \%)$ & \multirow{2}{*}{13.83} & \multirow{2}{*}{10.20} \\
\cline { 2 - 7 } & 21 & $11(26.82 \%)$ & $15(35.71 \%)$ & & \\
\cline { 2 - 7 } & 22 & $3(7.33 \%)$ & $3(7.15 \%)$ & 90.16 & 4.422 \\
\hline \multirow{2}{*}{ GPA } & $n=73$ & 90.12 & 108.68 & 108.36 & 7.271 \\
\hline
\end{tabular}

As can be seen in Table 1, the sampled students in both groups were approximately homogeneous and could be involved in the experiment.

\subsection{Instruments}

Two instruments were used to collect qualitative data for the study. These were a checklist for observers and a focus group questionnaire.

\subsection{Checklist for Observers}

The checklist was designed to monitor the sampled students' functional and linguistic abilities to use language for professional communication. The checklist consisted of 10 items distributed under the 
above abilities and used a 5-point Likert quality scale to evaluate the students' performance. The scale use measurement values ranging from 1 meaning 'inadequately' to 5 signifying 'excellently.'

The validation procedure of the checklist content that relied on recommendations of Spitzberg (2007), showed a sufficient item-level content validity index (IL-CVI) with values that were higher than 0.82 . The Kappa coefficient values for the checklist were higher than 0.83 which meant a 'good validity' of the instrument.

The 2-factor confirmatory factor analysis was also conducted to perform reliability analyses of the checklist (see Table 2). The population of 792 students was used as a sample to pilot the checklist. It used the principal component analysis with an Oblimin rotation.

Table 2: Results of factor loadings and reliability analysis, Cronbach's alpha $(\alpha)$, for the checklist subscales $(n=792)$

\begin{tabular}{l|c|c}
\hline \multirow{2}{*}{$\#$ of item } & \multicolumn{2}{|c}{ Subscales } \\
\cline { 2 - 3 }$\alpha$ (items on the scale) & Functional ability & Linguistic ability \\
\hline F1 & $.864(6)$ & $.877(4)$ \\
\hline$F_{2}$ & .659 & \\
\hline$F_{3}$ & .757 & \\
\hline F & .669 & \\
\hline F5 & .687 & \\
\hline F6 & .786 & .775 \\
\hline L7 & .696 & .758 \\
\hline L8 & & .748 \\
\hline L9 & & .786 \\
\hline L10 & & \\
\hline
\end{tabular}

The $\alpha$ values of .864 and .877 suggested that the subscales of the checklist could be used separately.

\subsection{Focus Group Interview}

Nine randomly selected students of the EG were hired for the interviews that lasted 30 minutes each. These were administered by the senior students who were instructed in conducting the interview. The focus group relied on 4 open-ended questions. The procedure complied with the recommendations of Latif and Dilshad (2013). The Cisco Webex web conferencing application was utilised to record the interviews. Following that, a verbatim transcription of the interviews was performed and the text was consolidated for the analyses. The themes were specified and assigned the codes.

\section{Results}

The study found that the training of student lawyers in message framing positively influenced their professional written and verbal communication proficiency. The research also specified the most effective activities for training in framing messages to influence the communication proficiency of student lawyers. It was established that sampled students positively perceived the training in framing messages. Below are presented the results of observations and focus groups.

\subsection{Results Drawn from Observations: Functional Ability VS Linguistic Ability}

The bar chart in Fig 2. illustrates how observers' scores for using functional language and language rules change throughout the training when a new type of message framing was introduced. As can be 
noticed in Fig 2, the values for students' functional abilities grew more than those for the linguistic ability which suggested that students seceded more in structuring the message to make it cohesive coherent, and easy to follow, using persuasion techniques and managing text length. The values in Fig 2 imply that the students also experienced improvements in their linguistic abilities such as using appropriate language, applying paraphrasing techniques relevantly, and presenting their arguments with sufficient grammar accuracy.

When rating the activities for training in framing messages that are useful for lawyers, the observers mentioned five framing message activities seen as the most effective. Those were as follows: gain and loss, storytelling, WASP, call-to-action, ethos, and pathos.

As can be seen in Figure 3, gain and loss, ethos and pathos, and storytelling were rated by the observers higher than WASP and call-to-action. These were considered by the observers to be the most appropriate for the lawyer job context.

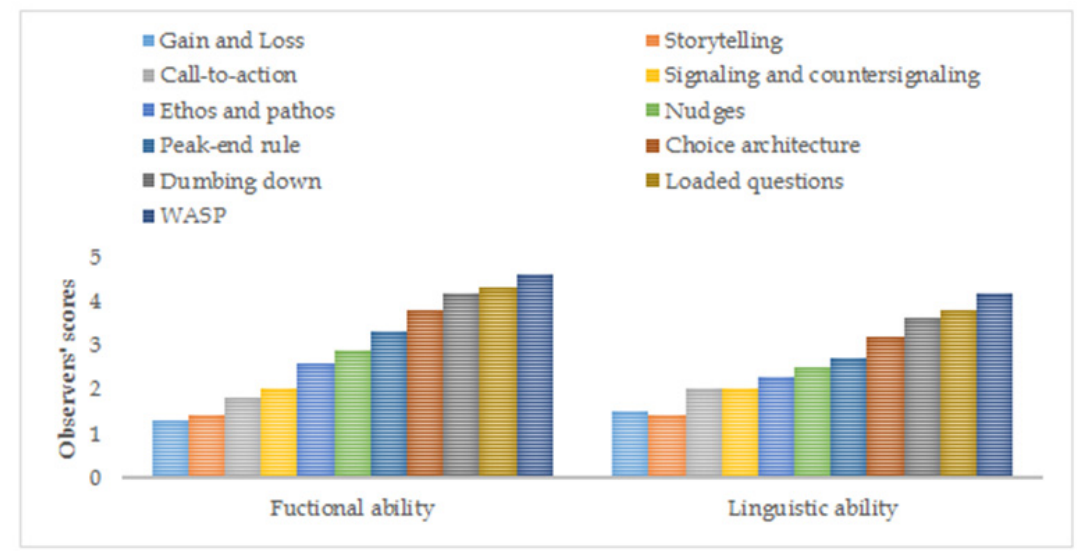

Figure 2: Observers' scores for using functional language and language rules in every type of training activity in message framing

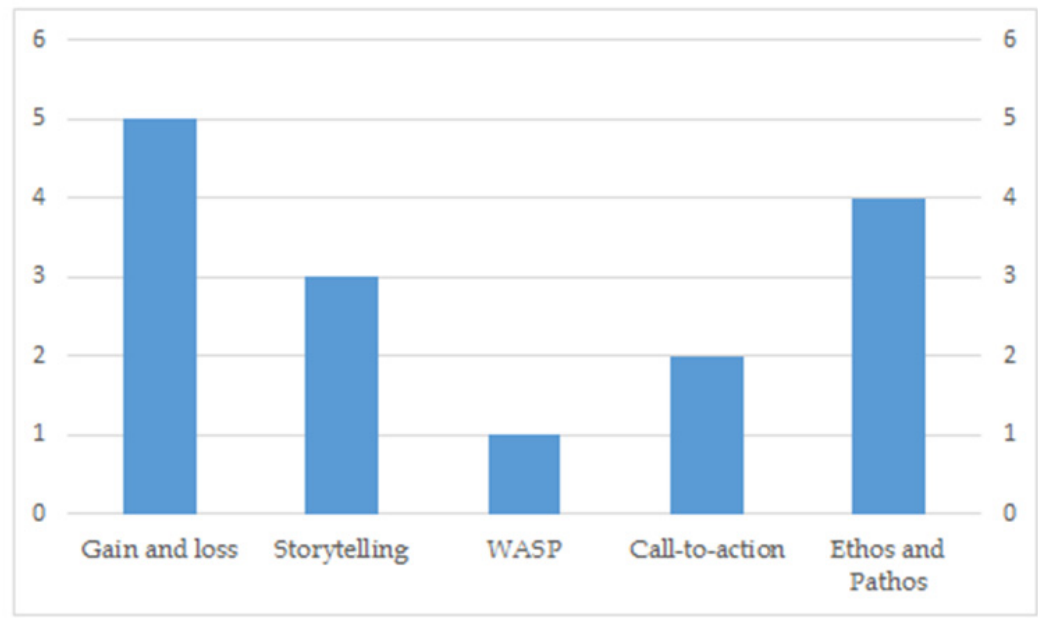

Figure 3: Results of rating the activities for training in framing messages by experts 


\subsection{Results of the Focus Group Interview}

A total of 9 randomly selected EG students participated in the focus group interview. The group of interviewees consisted of 4 males and 5 females aged 20-22 $(M=20.88 ; S D=0.7817)$. The average duration of the focus groups was $23: 86 \mathrm{~min}(S D=5.804)$. The student data were systemised to explain four main themes such as general impressions, benefits, dissatisfaction reasons, and suggestions (see Fig. 4).

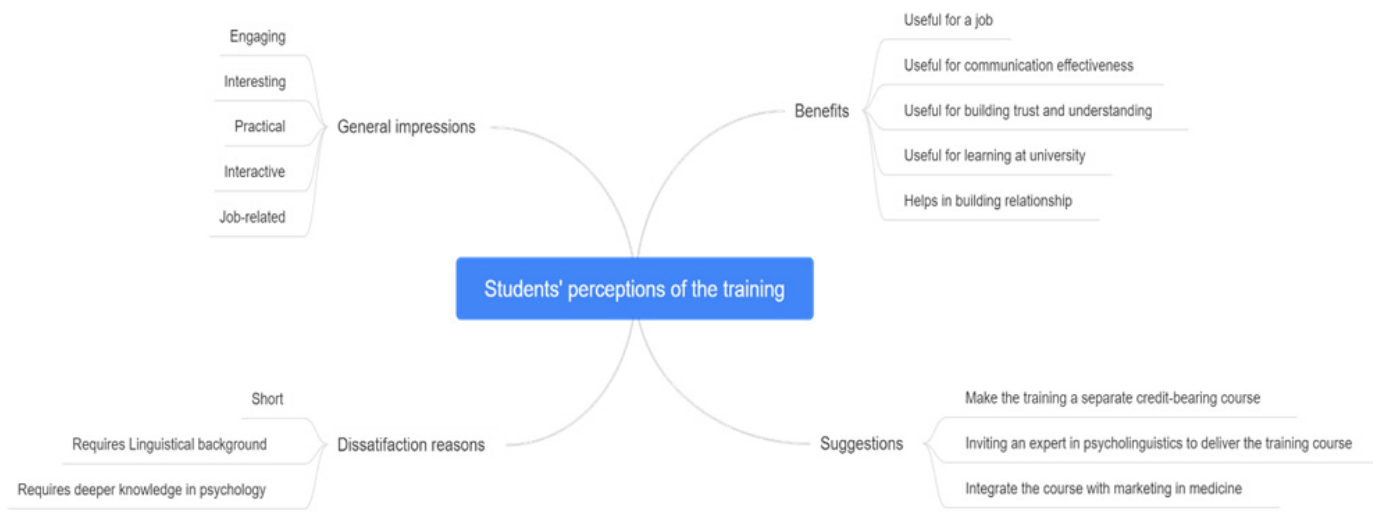

Figure 4: Mind map of themes and codes drawn from the interview

Data relating to students' general impressions of training in framing messages showed that they found this training interesting and engaging, practically useful for their jobs. The majority of students mentioned that they:

[... felt encouraged and involved in solving specific communication tasks. Before, I was always confused with the way I had to write or speak to persuade people to do things, but now I just use the templates to structure my thoughts ...]

[... felt more confident in speaking and writing on legal matters using plain language because got prompts for organising ideas. Communication became much easier and convenient...]

All interviewees mentioned feeling that this training address needs related to their future job, communication effectiveness, building trust and understanding, learning at university, building relationship. They stated that they:

[... experienced how communication could improve over such a short period... how good one's relations could become due to the simple 'communication tricks'...]

[...felt they 'received a key' to peoples' thoughts and they could influence people's decisions...]

Because of a lack of knowledge in psycholinguistics and psychology, 3 students felt uncomfortable about attending classes and felt disappointed when their peers commented on their messages. Three more students raised the duration of the course as having caused them to feel disappointed explaining that the training course was short to acquire necessary skills and gain sufficient confidence in framing messages.

[...at first, I was a little bit stereotypical and prejudiced about the language I should use in my writing and speaking with a client. I did not pay attention to words that can replace the bookish expressions and 
the power of those words to influence people...]

The consolidated responses for the question on suggestions found that 4 students recommended making this training a separate credit-bearing course. Two students proposed to invite an expert in psycholinguistics to deliver the course. Three other students advised integrating the course with marketing in medicine. Their reasoning was:

[... it was practical and pushed me to think critically...]

[... it relied on real cases and allowed me to feel as if I was doing a real job...]

[...communication seems to be more important than law enforcement measures or restrictions or fines...]

[... lawyer's job is about helping people thru communication, that's why it is vitally important to use easy-to-follow language structured in an easy-to-follow way...]

\section{Discussions}

The study was intended to identify how the training of student lawyers in message framing influences their professional written and verbal communication proficiency. It attempted to address the questions of what the most effective activities for training in framing messages to influence the communication proficiency of student lawyers were and how sampled students perceived the training in framing messages.

The strength of the study is in a specifically structured instructional model that relied on a 'bolton' module delivered throughout the entire elective course in Legal Rhetoric. It used 14 message frames such as gain and loss, storytelling, call-to-action, signalling and countersignalling, ethos and pathos, nudges, peak-end rule, choice architecture, dumbing down, loaded questions, and WASP (welcome-ask-suggest-part).

The data drawn from observations showed that the observers' scores for using functional language and language rules increased throughout the training when a new type of message framing was introduced. The values for students' functional abilities grew more than those for the linguistic ability which suggested that students seceded more in structuring the message to make it cohesive coherent and easy to follow, using persuasion techniques and managing text length. Those values implied that the students also experienced improvements in their linguistic abilities such as using appropriate language, applying paraphrasing techniques relevantly, and presenting their arguments with sufficient grammar accuracy.

When rating the activities for training in framing messages that are useful for lawyers, the observers mentioned five framing message activities seen as the most effective. Those were as follows: gain and loss, storytelling, WASP, call-to-action, ethos, and pathos. Gain and loss, ethos and pathos, and storytelling were rated by the observers higher than WASP and call-to-action. These were considered by the observers to be the most appropriate for the lawyer job context.

The student data yielded from the interview were systemised to explain four main themes such as general impressions, benefits, dissatisfaction reasons, and suggestions. Data relating to students' general impressions of training in framing messages showed that they found this training interesting and engaging, practically useful for their jobs. The interviewees mentioned feeling that this training address needs related to their future job, communication effectiveness, building trust and understanding, learning at university, building relationship. Because of the lack of knowledge in psycholinguistics and psychology, three students felt uncomfortable about attending classes and felt disappointed when their peers commented on their messages. Three more students raised the duration of the course as having caused them to feel disappointed explaining that the training course was short to acquire necessary skills and gain sufficient confidence in framing messages. The consolidated responses for the question on suggestions found that four students recommended making this training a separate credit-bearing course. Two students proposed to invite an expert in psycholinguistics to deliver the course. Three other students advised integrating the course with 
marketing in medicine.

The study is consistent with theory and previous findings. It aligns with the concept of framing seen as a technique that is used to reduce the vagueness of intangible themes by contextualising the information from the perspective of the recipients' prior experience and knowledge. It agrees with Gouvin, Koops, Moliterno, Morgan, and Newman (2019) who stated that communication aimed at building lawyer-client relationships and control require the lawyers to be influential which supposes the student lawyers to focus on such communication skills as interviewing, counselling, negotiation, and presentations. It goes in line with Chesebro and Martin (2010) who found that frames can be used by the instructors to influence students' perceptions and behaviours. The study agrees with Rapoport (2020) who stated that framing a discussion in the educational settings can help students majoring in law develop the skill and habit of building well-structured and persuasive messages and arguments. The author considers this instructional approach a curricular innovation.

\section{Conclusion}

The study found that a specifically structured instructional model that relied on a 'bolt-on' module in message framing delivered throughout the entire elective course in Legal Rhetoric positively influenced students' professional written and verbal communication proficiency. The data drawn from observations showed that students' abilities to use functional language and language rules increased throughout the training. The values for students' functional abilities grew more than those for the linguistic ability which suggested that students seceded more in structuring the message to make it cohesive coherent and easy to follow, using persuasion techniques and managing text length. Those values implied that the students also experienced improvements in their linguistic abilities such as using appropriate language, applying paraphrasing techniques relevantly, and presenting their arguments with sufficient grammar accuracy. When rating the activities for training in framing messages that are useful for lawyers, the observers mentioned five framing message activities seen as the most effective. Those were as follows: gain and loss, storytelling, WASP, call-to-action, ethos, and pathos. Gain and loss, ethos and pathos, and storytelling were rated by the observers higher than WASP and call-to-action. These were considered by the observers to be the most appropriate for the lawyer job context. Data relating to students' general impressions of training in framing messages showed that they found this training interesting and engaging, practically useful for their jobs.

\section{Recommendations}

Practitioners should make the training of this kind to be a separate credit-bearing course and they should involve an expert in psycholinguistics to deliver the course. Researches should study how training in message framing integrated into the course of marketing in medicine can impact students' entrepreneurial competence.

\section{Limitations}

The key limitation is related to the research design because there is no random selection between EG and CG under the non-equivalent control group post-test only design (Price, 2016).

\section{Acknowledgement}

We are thankful to experts, observers, and interviewers for helping in the research. We are also thankful to the sampled students for their agreement to take the challenge when training in framing messages. 


\section{References}

Arowolo, S. O. (2017). Understanding framing theory. Retrieved from: https://www.researchgate.net/publication /317841096_UNDERSTANDING_FRAMING_THEORY?channel=doi\&linkId=594d9b9dof7egbe7b2d661e4\&sh owFulltext=true (accessed February 2, 2021).

Bekrycht, T. (2014). Communication models in law. Masaryk University Journal of Law and Technology, 8(2), 157170.

Cheng, T., Woon, D. K., \& Lynes, J. K. (2011). The use of message framing in the promotion of environmentally sustainable behaviors. Social Marketing Quarterly, 17(2), 48-62. https://doi.org/10.1080/15245004.2011.570859

Chesebro, J., \& Martin, M. (2010). Message framing in the classroom: The relationship between message frames and student perceptions of instructor power. Communication Research Reports, 27(2), 159-170. https://doi.org/10.108o/08824091003738107

Chong, D., \& Druckman, J. N. (2007). A Theory of framing and opinion formation in competitive elite environments. Journal of Communication, 57(1), 99-118. https://doi.org/10.1111/j.1460-2466.2006.00331.x

Etikan, I., Musa, S. A., \& Alkassim, R. S. (2016). Comparison of convenience sampling and purposive sampling. American Journal of Theoretical and Applied Statistics, 5(1), 1-4. https://doi.org/10.11648/j.ajtas.20160501.11

Hanacek, J. (n.d.). Phases of the research process. Retrieved from: https://cashp.columbian.gwu.edu/sites/g

/files/zaxdzs1746/f/downloads/4Phases_of_research_process_-_Hanacek.doc (accessed February 2, 2021).

Harley, A. (2016, June 19). Prospect theory and loss aversion: How users make decisions. Retrieved from: https://www.nngroup.com/articles/prospect-theory/ (accessed February 2, 2021).

Hayes, A. F. (2005). Statistical methods for communication science. 1st edition. New York, NY: Routledge.

Gouvin, E. J., Koops, K. M., Moliterno, J. E., Morgan, C., \& Newman, C. D. (2019). Teaching communication skills in transactional simulations. Transactions: The Tennessee Journal of Business Law, 20, 429-458.

Keyworth, C., Nelson, P. A., Bundy, C., Pye, S. R., Griffiths, C. E. M., \& Cordingley, L. (2018). Does message framing affect changes in behavioural intentions in people with psoriasis? A randomized exploratory study examining health risk communication. Psychology, Health \& Medicine, 23(7), 763-778. https://doi.org/10.108o/13548506.2018.1427876

Latif, M. I., \& Dilshad, R. M. (2013). Focus group interview as a tool for qualitative research: An analysis. Pakistan Journal of Social Sciences, 33(1), 191-198.

Lazaraton, A., \& Riggenbach, H. (1990). Oral skills testing: A rhetorical task approach. Issues in Applied Linguistics, 1(2), 196-217.

Lee, H.-C., Liu, S.-F., \& Cheng, Y.-C. (2018). Positive or Negative? The Influence of message framing, regulatory focus, and product type. International Journal of Communication 12, 788-805.

Li, X., Jain, S. S., Shen, Y. A., \& Jain, S. P. (2020). Power and message framing: the case of comparative advertising. Customer Needs and Solutions, 7(1), 1-9. https://doi.org/10.1007/s40547-020-00110-9

Mass Communication Theory. (n.d.). Framing theory. Retrieved from: https://masscommtheory.com/theoryoverviews/framing-theory/ (accessed February 2, 2021).

Pervan, S. J., \& Vocino, A. (2008). Message framing: keeping practitioners in the picture. Marketing Intelligence $\mathcal{E}$ Planning, 26(6), 634-648. https://doi.org/10.1108/02634500810902875

Price, P. C. (2016). Research methods in psychology. Minneapolis, MN: Libraries Publishing.

Rapoport, N. B. (2020). Training law students to maintain civility in their law practices as a way to improve public discourse. North Carolina Law Review, 98, 1144-1183.

Reinard, J. C. (2006). Communication research statistics. Thousand Oaks, CA: SAGE Publications Inc.

Richardson, B. (2010, October 9-12). Communicate on purpose-the art of framing. Paper presented at PMI Global Congress 2010, Project Management Institute. Retrieved from: https://www.pmi.org/learning/library /communicate-framing-messages-facilitative-leadership-6640 (accessed February 2, 2021).

Sheil, E. (2017, March 17). Why framing your message matters. Retrieved from: https://www.prweek.com/article/1427827/why-framing-message-matters (accessed February 2, 2021).

Smith, J. (2020, June). 7 skills for a successful law career. Retrieved from: https://www.prospects.ac.uk/jobs-andwork-experience/job-sectors/law-sector/7-skills-for-a-successful-law-career (accessed February 2, 2021).

Spitzberg, B. H. (2007). CSRS: The conversational skills rating scale. An instructional assessment of interpersonal competence. 2nd edition. Washington, DC: National Communication Association.

Wicks, R. H. (2005). Message framing and constructing meaning: An emerging paradigm in mass communication research. Annals of the International Communication Association, 29(1), 335-362. https://doi.org/10.1080/23808985.2005.11679052 


\section{Appendix A: Checklist for Observers}

\begin{tabular}{|c|c|c|c|c|c|c|}
\hline \multirow{2}{*}{ Ability } & \multirow{2}{*}{ Item } & \multicolumn{5}{|c|}{ 5-point Likert quality scale } \\
\hline & & 1 & 2 & 3 & 4 & 5 \\
\hline \multirow{6}{*}{ Functional } & 1. Narration is cohesive and coherent. & & & & & \\
\hline & 2. The message is structured appropriately to comply with a specific frame. & & & & & \\
\hline & 3. The message is easy to follow. & & & & & \\
\hline & 4. The transition signals are used. & & & & & \\
\hline & 5. The persuasion techniques are used. & & & & & \\
\hline & 6. The word limit is managed. & & & & & \\
\hline \multirow{4}{*}{ Linguistic } & 7. The language is used precisely and appropriately for the task/assignment. & & & & & \\
\hline & 8. The range of vocabulary is adequate and broad for accomplishing tasks. & & & & & \\
\hline & 9. Grammar accuracy is adequate. & & & & & \\
\hline & 10. Paraphrasing is used to explain more difficult legal concepts. & & & & & \\
\hline
\end{tabular}

Note: 1 = Inadequately; 2 = Fairly; 3 = Adequately; 4 = Well; 5 = Excellently.

\section{Appendix B: Questionnaire for the Focus Group}

1. How do you feel about training in framing messages to influence your communication proficiency?

2. How did this training address your educational/professional needs?

3. What made you feel dissatisfied with the training?

4. What would you suggest we do to improve the training? 